\begin{tabular}{llll}
\hline Submission: 25/07/2018; & $1^{\text {st }}$ round notif.: 07/02/2019; & New version: 16/04/2019; & $2^{\text {nd }}$ round notif.: 12/05/2019 \\
Camera ready: 18/06/2019; & Edition review: 20/11/2019; & Available online: $16 / 02 / 2020 ;$ & Published: 16/02/2020 \\
\hline
\end{tabular}

\title{
Co-designing Gamified Intelligent Tutoring Systems with Teachers
}

\author{
Diego Dermeval \\ Center of Excellence for Social Technologies (NEES), \\ Faculty of Medicine, Federal University of Alagoas \\ diego.matos@famed.ufal.br
}

\author{
Ig Ibert Bittencourt \\ Center of Excellence for Social Technologies (NEES), \\ Computing Institute, Federal University of Alagoas \\ ig.ibert@ic.ufal.br
}

\begin{abstract}
Researchers are increasingly interested in Gamified Intelligent Tutoring Systems (ITS) to provide adaptive instruction and to enhance engagement of students. However, although teachers are demanding to be active users of gamified ITS, they have been not considered as first-class citizens in the design of these kinds of systems. In order to contribute to the active and customized use of gamified ITS by teachers, three technical problems should be considered. First, designing ITS is very complex (i.e., considering different theories, components, and stakeholders) and including gamification may significantly increase such complexity and variability. Second, gamified ITS features can be used depending on several elements (e.g., educational level, knowledge domain, gamification and ITS theories, etc). Thus, it is imperative to take advantage of theories and practices from both topics to reduce the design space of these systems. Third, in order to effectively aid teachers to actively use such systems, it is needed to provide a simple and usable solution for them. To target these problems, in this paper, we present a solution for authoring gamified ITS by teachers that makes use of an ontology-based feature model (OntoSPL) to deal with the variability at runtime and takes advantage of an ontology (GaTO) that connects gamified ITS theories and design practices to constrain the variability space for designing these systems. Our main results indicate that teachers have a high acceptance level (i.e., ease of use, usability, and low complexity) in the design of gamified ITS using the authoring solution, customizing their own gamified tutors in less than five minutes. These results indicate a promising way to explore the use of authoring tools, ontologies, and software engineering to take advantage of both artificial intelligence techniques (mainly for aiding adaptation for students) as well as on the human intelligence of teachers to co-design gamified intelligent tutoring systems.
\end{abstract}

Keywords: Gamified Intelligent Tutoring Systems; Gamification; Intelligent Tutoring Systems; ITS Authoring Tools

Cite as: Dermeval, D., \& Bittencourt, I. I. (2020). Co-designing Gamified Intelligent Tutoring Systems with Teachers. Brazilian Journal of Computers in Education (Revista Brasileira de Informática na Educação - RBIE), 28, 73-91. DOI: 10.5753/RBIE.2020.28.0.73 


\section{Introduction}

Intelligent tutoring systems (ITS) are concerned with the use of artificial intelligence techniques for performing adaptive tutoring to learners according to what they know about the domain (Sleeman \& Brown, 1982). There is recent and reliable evidence supporting the effectiveness of using ITSs (du Boulay, 2016). Thus, well-designed ITS can successfully complement and substitute other instructional models at all educational levels and in many common academic subjects (Ma, Adesope, Nesbit, \& Liu, 2014). However, students may become disengaged or bored during the learning process by using ITSs, particularly in long-term instruction; and for those students who continue to interact despite the lack of interest, boredom may trigger a vicious cycle that prevents them from actively reengaging in constructive learning processes (Baker, D’Mello, Rodrigo, \& Graesser, 2010).

Aiming to enhance student motivation and engagement during ITS instruction, researchers have been increasingly using gamification (Deterding, Dixon, Khaled, \& Nacke, 2011) along with ITS. The use of gamification aims to engage and motivate users to achieve better results and create enhanced solutions and experiences (Hamari, Koivisto, \& Sarsa, 2014). In the educational context, gamification may motivate action, promote learning, and facilitate problem-solving as well as drive desired learning behaviors (Seaborn \& Fels, 2015).

However, in general, ITSs are not personalized according to teachers' preferences, for instance, the one-size-fits-all approach (ProjectTomorrow, 2013, 2014; Lemann, 2015). Teachers are different with respect to expectations and methodologies for using these systems, which could be applied in different contexts that may vary regarding their domains, educational levels, system features, and so on. Indeed, teachers are much more passive than active in the design of ITS. Meanwhile, teachers are increasingly demanding to act as active users of adaptive and intelligent educational systems. For instance, a recent survey (ProjectTomorrow, 2014) with 41,805 K-12 teachers in the USA reports that more than half of them consider learning how to use these technologies the most important item for their professional development. Another survey (ProjectTomorrow, 2013) with aspirants teachers in the USA reports that they consider the access to adaptive technologies as one of the main factors that will determine their future success as teachers. In Brazil, a survey with 1,000 public middle-school teachers pointed out that more than $80 \%$ of them rely on the potential of students' adaptive learning; $92 \%$ percent of the teachers also demand training to use educational technologies (Lemann, 2015).

Teachers also say that games enable them to differentiate instruction (60\%) and to create classrooms that are more learner centric (44\%) (ProjectTomorrow, 2014) and that by using gamification they can motivate students because of the intrinsic entertaining nature of games and can facilitate students' learning via entertainment and a higher motivation (Martí-Parreño, SeguíMas, \& Seguí-Mas, 2016). As such, these studies suggest that teachers show a positive attitude towards gamification, but there is not an intense use in their courses due to the lack of time and other resources (e.g., classroom setting) available, lack of time to prepare materials and training in gamification (Martí-Parreño et al., 2016).

All things considered, to leverage the active participation of teachers in the design of gamified ITS, we have faced three research problems. First, designing these systems present a huge variability (Silva, Costa, \& Bittencourt, 2012) and all feature combinations might not be necessarily effective for learners (Woolf, 2010). Second, gamification and ITS theories and design

practices should also be considered to constrain the design space of gamified ITS (Nacke \& Deterding, 2017) to aid designing more effective tutors. Third, assuming that a teacher intends to customize such a complex system, it is imperative to make the design process simple, usable and 
not requiring advanced technical skills, e.g., on programming, artificial intelligence and/or software engineering (Dag, Durdu, \& Gerdan, 2014; Sottilare, Graesser, Hu, \& Brawner, 2015).

In this work, we describe how we have been exploring the use of software engineering techniques, - i.e., feature modeling (Czarnecki, Peter Kim, \& Kalleberg, 2006) and software product line (Clements \& Northrop, 2001) - ontologies (Gruber, 1993) and ITS authoring tools (Murray, 2003) to combine teachers and artificial intelligence for co-designing gamified intelligent tutoring systems. On the one hand, we have explored how to formally represent the design variability for designing such systems as well as the knowledge about theories and evidence regarding the application of gamification in ITS relying on the use of ontologies; to favor the use of artificial intelligence techniques. On the other hand, we depict how we might leverage the human intelligence of teachers in the design of such systems relying on the use of theory and evidence-aware authoring tools that automatically reason on such ontologies.

This paper is organized as follows. Section 2 presents the background on ITS and gamification. Section 3 presents an overview of our contributions toward the co-design of gamified intelligent tutoring systems with teachers. Section 4 presents the reference feature model for gamified ITS that we propose as well as the ontology-based feature modeling approach developed. Section 5 describes the objectives related to the understanding of gamification design practices, the definition of a gamification domain ontology, and an integrated ontological model that connects gamification to existing ITS ontologies. Section 6 presents the authoring tool that we have developed to enable teachers designing gamified ITS considering the ontologies developed. In Section 7, we describe our related works. Finally, in Section 8, we conclude this chapter by summarizing our contributions and pointing out further researches.

\section{Background}

In this section we present the main theoretical concepts involved in this work, that are intelligent tutoring systems and gamification.

\subsection{Intelligent Tutoring Systems}

Sleeman and Brown (1982) define Intelligent Tutoring System as a computer-based program that uses artificial intelligence to represent knowledge and to conduct an adaptive interaction with students. According to their definition, an ITS should have in its basic structure features such as, (i) what to teach, (ii) how to teach and (iii) teaching for whom. Shute \& Psotka (1994) noted that almost all researchers agreed that the most critical feature provided by ITSs is the student modeling. The next most frequently cited feature is adaptive behavior.

A broader definition (Ma et al., 2014) qualify ITS as a computer system that for each student: (i) performs tutoring functions, for example, by presenting information to be learned, by asking questions or assigning learning tasks, by providing feedback or hints, by answering questions posed by students or by offering prompts to provoke cognitive, motivational or metacognitive change; (ii) computes inferences from students responses and constructs either a persistent multidimensional model of the student's psychological states or locates the student's current psychological state in a multidimensional domain model; and (iii) uses the student modeling functions to adapt one or more of the tutoring functions.

It is generally accepted that an ITS has four major components (Sleeman \& Brown, 1982; Sottilare et al., 2015; Woolf, 2010): the domain model, the student model, the 
tutoring/pedagogical model, and the user interface model. These components are described as follows:

1. A domain model represents the knowledge the student is intended to learn. It normally contains the ideal expert knowledge and also the bugs, mal-rules, and misconceptions that students periodically exhibit. The model is a set of logical propositions, production rules, natural language statements, or any suitable knowledge representation format (e.g., ontologies). Generally, it requires significant knowledge engineering to represent a domain so that other parts of the tutor can access it.

2. A student model represents relevant aspects of the student's knowledge determined by the student's responses to questions or other interactions with the interface. There are many methods for representing information about the student. Two commonly used techniques are overlay models and Bayesian networks (Beck, Stern, \& Haugsjaa, 1996). In the overlay model, student's knowledge is considered to be a subset of the expert's knowledge, whereas bayesian networks probabilistically reason about a student's knowledge state based on his interactions with the tutor. Each node in the network has a probability indicating the likelihood of the student "knowing" that piece of knowledge.

3. A tutor model (also known as pedagogical model or instructional model) represents instructional strategies. It takes the domain and student models as input and selects tutoring strategies, steps, and actions on what the tutor should do next in the exchange. It is a model of how someone skilled in a particular domain represents the knowledge.

4. An interface model interprets the learner's contributions through various input media (speech, typing, clicking) and produces output in different media (text, diagrams, animations, agents). This model is often constrained to the subject domain (e.g., algebra).

\subsection{Gamification}

Before defining gamification, we need to conceptualize games and differentiate from them. There are lots of descriptions and conceptual expositions about games. Salen \& Zimmerman (2004) define games as "systems in which players engage in an artificial conflict, defined by rules, that results in a quantifiable outcome”. Moreover, as stated by Seaborn \& Fels (2015), games emerge from a variety of combinations of rules, structure, voluntariness, uncertain outcomes, conflict, representation and resolution criteria in different proportions, and whether an experience is a game of gameful is determined by participant perception.

Gamification takes the power of games and applies it to a given context to solve a problem. An important aspect of gamification understanding of what game elements are adequate in each problem and situation. Werbach \& Hunter (2012) describe game elements as smaller pieces used to define building blocks that form the integrated gameplay experience. According to the same authors, these game elements are included in the dynamics, mechanics and components categories, as described below and showed in Figure 1. 


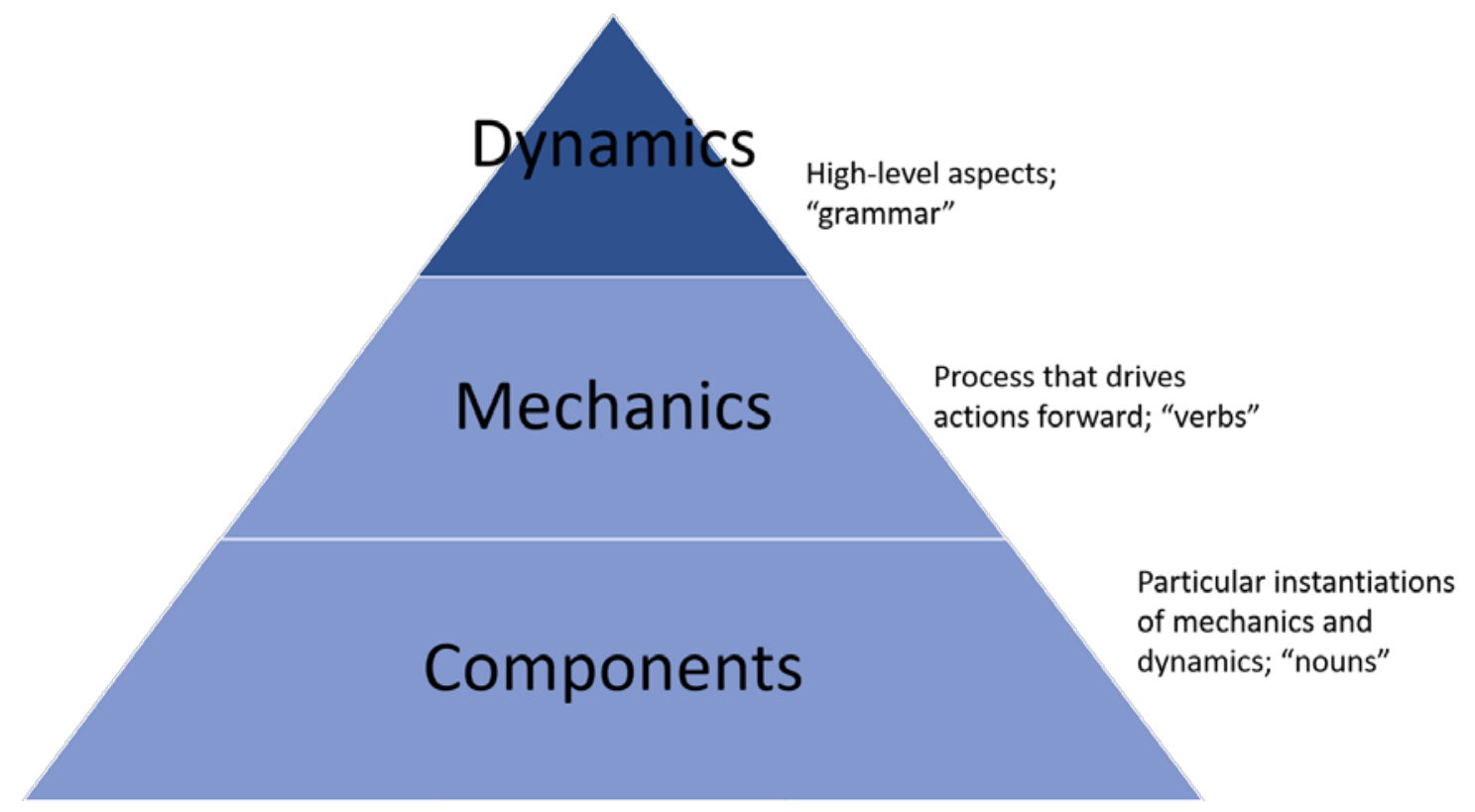

Figure 1 - Pyramid of elements. Adapted from Werbach (2012)

- Game dynamics - the "big picture" aspects of the gamified system that you have to consider and manage but which can never directly enter into the game. For instance, constraints, emotions, narrative, progression, relationships, and personalization.

- Game mechanics - the basic processes that drive the action forward and generate player engagement. For instance, challenges, chance, competition, cooperation, feedback, resource, acquisition, rewards, transactions, turns, win states, and profiles.

- Game components - the specific instantiations of mechanics and dynamics. For instance, achievements, badges, collections, leaderboards, levels, notifications, points, progress bars, quests or missions, status, teams, virtual goods, and so on.

While there is no standard conceptualization of gamification, most authors agree that gamification is generally defined as the use of game elements and mechanics in non-game contexts. Seaborn and Fels (2015) summarize the intersection of gamification conceptualizations provided by Deterding et al. (2011), Werbach \& Hunter (2012), and Huotari \& Hamari (2012) and presents an emerging standard definition of gamification: the intentional use of game elements for a gameful experience of non-game tasks and contexts. As games elements, the authors consider patterns, objects, principles, models, and methods directly inspired by games.

\section{Overview of the contributions}

In this work, we have explored the use of software engineering techniques, i.e., feature modeling and software product line (Clements \& Northrop, 2001), ontologies (Gruber, 1993) and ITS authoring tools (Murray, 2003) to design and implement an authoring solution to provide for teachers a way to actively customize gamified ITS features. Figure 2 presents an overview of this work, mapping the specific objectives of the thesis. To target the first problem, we defined a reference feature model for representing the variability of gamified ITSs (objective 1) and conceptualized an ontology for representing the reference feature model (objective 2). To address the second problem, we identified evidence-supported combinations of game design elements that might be more amenable to be effective for achieving particular behaviors in the ITS domain (objective 3), we also developed a gamification domain ontology considering theories, frameworks, and design practices (objective 4), and developed an integrated ontological model 
that connects the gamification domain ontology with existing ITS ontologies (objective 5). To target the third problem, we developed an authoring solution to provide for teachers a way to customize gamified ITS features (objective 6) taking into account the ontology-based feature model to formally deal with the high variability of gamified ITS at runtime as well as the ontological model to consider theories and evidence-supported gamification design practices for aiding the design of gamified ITS by teachers. We group these objectives in three main contributions that are further described in the following sections.

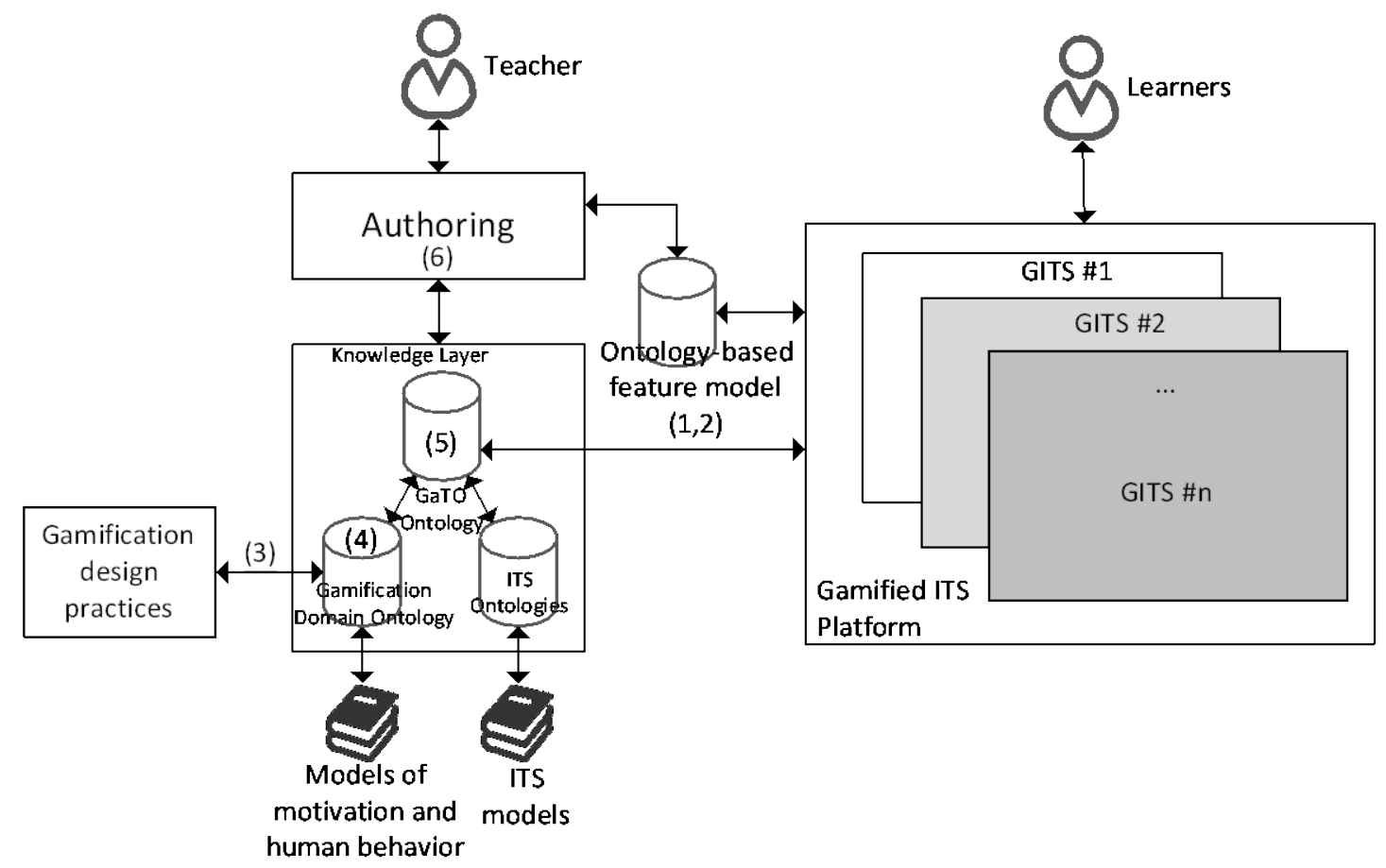

Figure 2 - Overview of the objectives of this work.

\section{Gamified ITS ontology-based feature model}

To manage the high variability of gamified ITS features, we first specified a reference feature model for representing the variability of gamified ITS. We have identified the common and variable features of these systems by (i) analyzing the features presented in an SPL (Software Product Line) designed for classic ITSs (Silva et al., 2012); (ii) analyzing the features of ITSs that use gamification in industrial settings (i.e., MeuTutor ${ }^{1}$ and Duolingo); (iii) conducting interviews with MeuTutor development team to gather information about new requirements that would be considered in future versions of Meu Tutor ITSs aiming to foresee variation points and variant features; and (iv) analyzing gamification (Werbach \& Hunter, 2012; Seaborn \& Fels, 2015; Hamari et al., 2014; de Sousa Borges, Durelli, Reis, \& Isotani, 2014) and ITS - i.e., (Sottilare et al., 2015; Woolf, 2010; Sleeman \& Brown, 1982) - features investigated in the literature. Figure 3 illustrates an excerpt of the resulting features diagram; the full diagram is available in the thesis which is cited in (Dermeval and Bittencourt, 2017).

\footnotetext{
${ }^{1}$ Brazilian company with ITS solutions.
} 


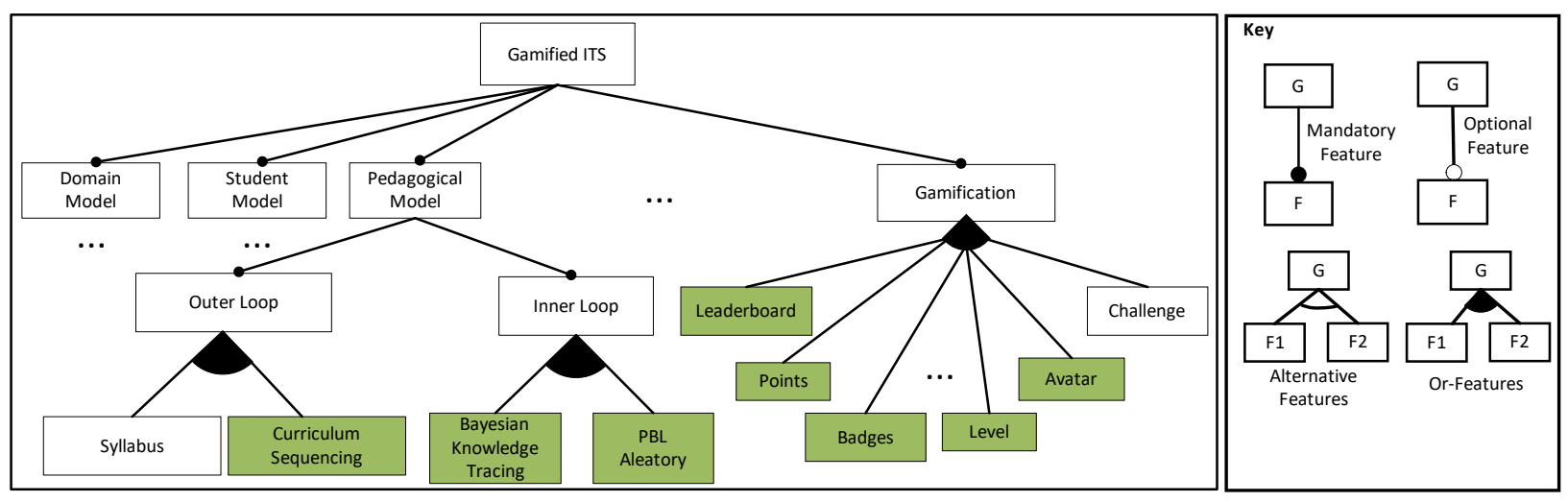

Figure 3 - Excerpt of the gamified ITS feature model in the FODA notation

To represent the gamified ITS feature model in a way that it could be automatically reasoned by software for managing the reconfiguration of gamified ITS according to preferences received as input from teachers using an authoring tool, we also developed an ontology-based feature modeling approach (Dermeval et al., 2015), called OntoSPL. The feature model represented in this approach might also be used to integrate an authoring solution to third-party gamified ITS platforms, as illustrated in Figure 2. To use OntoSPL for specifying our gamified ITS feature model, it is necessary to import the OntoSPL ontology (implemented in an OWL file) and create a set of OWL individuals to represent the feature model of gamified ITSs. As such, the new OWL file that represents the gamified ITS feature model is updated with OWL individuals. In this way, a particular configuration of gamified ITS (e.g., the green features of Figure 3) can be defined in the ontology.

\subsection{Evaluation and statistical results}

To evaluate OntoSPL, we conducted a controlled experiment (Dermeval et al., 2015) ${ }^{2}$ that compares OntoSPL (which is based on OWL instances/individuals) and a well-known ontology based on OWL classes and properties in changing scenarios. The experiment included ten participants in academic settings. Data gathered from this experiment was analyzed using descriptive and inferential statistics. The results of this experiment indicated that using OWL individuals (OntoSPL ontology) is more flexible (p-value $\left.=2.2 e^{-16}\right)$ and demands less time (pvalue $=0: 0006058$ ) for changing than the one based on OWL classes and properties. Based on these results, we moved forward to use this approach in the context of our gamified ITS feature model. Our intention was to rely on the flexibility capabilities of this approach to enable the automatic analysis of the variability of these systems.

\section{GaTO: Gamified Tutoring Ontology}

Our second contribution aims to target the problem of constraining the design space of gamified ITS considering theories and design practices to aid humans (i.e., teachers) in the effective customization of gamified tutors. As such, we defined an ontological model that connects gamification concepts and design principles to ITS concepts. We formalized a gamification domain ontology that represents core concepts about gamification as well as concepts considering

\footnotetext{
${ }^{2}$ More details about this controlled experiment can be found in (Dermeval et al., 2015).
} 
specific gamification theories and frameworks; we also conceptualized in the ontology evidencesupported gamification design practices, identified through the analysis of the literature. Then, we integrated the concepts formalized in the gamification domain ontology to ITS concepts defined in an existing ITS ontology to specify an ontological model for gamified tutoring, called GaTO.

Researchers are increasingly investigating the effects of gamification and game design elements in education (Nacke \& Deterding, 2017). For instance, several works included in systematic literature reviews (Hamari et al., 2014; de Sousa Borges et al., 2014; Seaborn \& Fels, 2015) present combinations of game design elements that might be more amenable to effectively achieve particular behaviors. As such, we analyzed the empirical works that provide some piece of evidence for using particular combinations of game design elements to target specific behaviors in the e-learning domain. Based on this analysis, we linked some game design elements with the behavioral outcomes the elements help to achieve. As a result, six main behavioral outcomes were identified and are shown in Table 1).

Table 1 - Summary of target behaviors and game design elements

\begin{tabular}{ll}
\hline Target Behavioral Outcome & Game Design Elements \\
\hline Participation & Story, Rewards, Badges, Levels, Challenge, Leaderboard, Points \\
\hline Performance & Story, Feedback, Rewards, Badges, Levels, Challenge, Leaderboard, Points \\
\hline Competition & Leaderboard, Points \\
\hline Enjoyment & Story, Rewards, Badges, Avatars, Challenge, Points \\
\hline Exploration & Levels, Challenge, Boss Fight \\
\hline Effectiveness & Leaderboard, Badges, Points \\
\hline
\end{tabular}

The mapping of behavioral outcomes and motivation affordances (i.e., game design elements) are used to constrain the design space of gamified ITS considering empirical studies on the topic as well as used in the conceptualization of a gamification domain ontology. We represent core concepts (e.g., gamification definition, game design element, player model, and so on) in the GaDO-core ontology regarding gamification domain and specific concepts (e.g., 6D framework, gamification design practices, BrainHex player type, and so on) are represented in the GaDO-full ontology. In this way, the concepts of these ontologies are connected to represent the gamification domain ontology. To develop these ontologies, we used the METHONTOLOGY approach, which is a well-known and broadly used ontology engineering methodology (Gómez-Pérez, 1996).

The concepts of GaTO ontology represent the core concepts involved in a gamified intelligent tutoring system. As seen in Figure $4^{3}$, besides including the three main ITS components - i.e., Student Model, Domain Model, and Pedagogical Model - a Gamified ITS also has a Gamification Model. The Student Model is connected to the ITS ontology through the Behavioral Knowledge concept, which is the representation of how a student behaves in the tutor, according to (Dillenbourg \& Self, 1992). It is also connected to the Player concept of the GaDO-core ontology to include students' behaviors as players. The Pedagogical Model is connected to the Instructional Plan (Du Boulay \& Luckin, 2001) concept to represent the tutoring strategies that could be used in the tutor. The Domain Model is, actually, a concept from the ITS ontology

\footnotetext{
${ }^{3}$ The implementation of this ontology is available at https://goo.gl/qtM6Ps
} 
provided by Bittencourt, Costa, Silva, \& Soares (2009) and is related to the Curriculum concept. In turn, a Curriculum has a set of Resources, also referred as learning objects. Despite been suppressed in Figure 4 for clarity purposes, these resources can be of several types, for instance, Problem, Content, Concept, Question, Essay and so on. The Gamification Model is connected to the Activity Loops designed for that gamified tutor. Furthermore, the Action concept from the GaDO-full ontology, which is part of a particular Engagement Loop, makes use of Resources from the ITS ontology. This relationship enables that a specific Engagement Loop design considers the interaction with Resources from an ITS Domain Model.

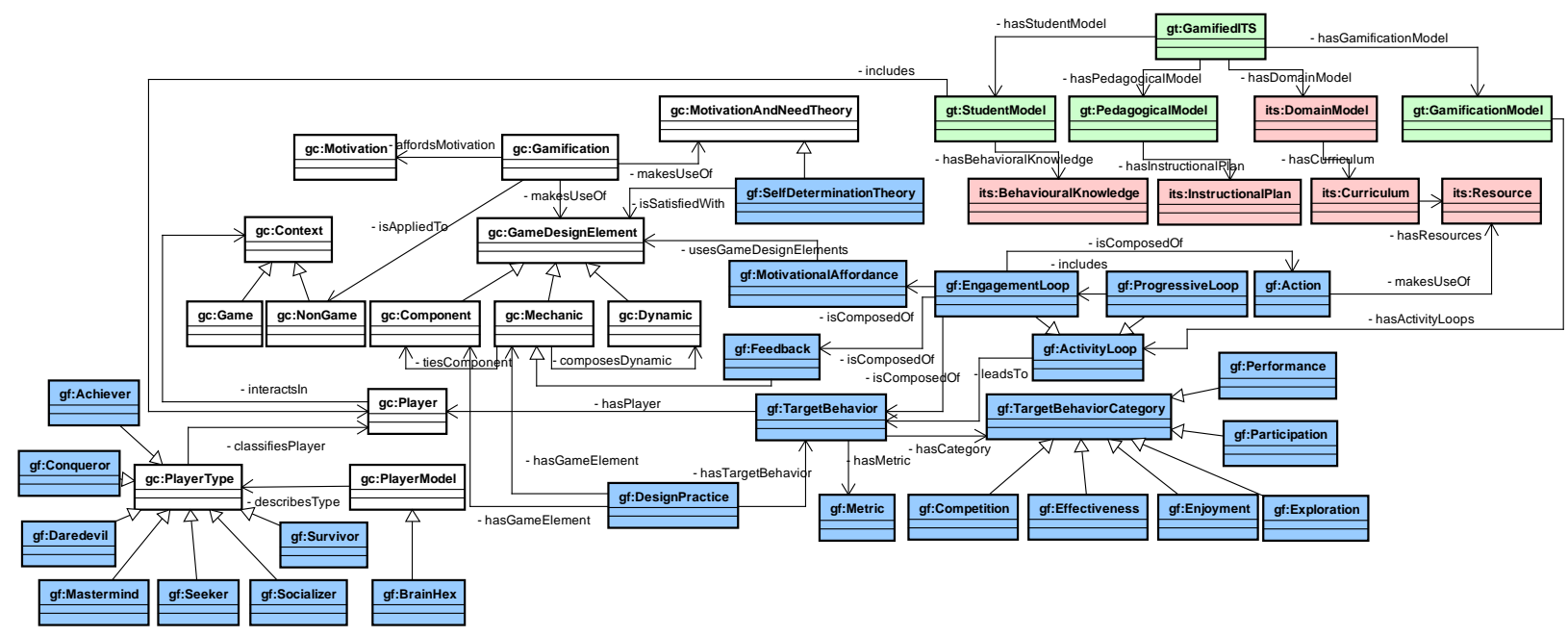

Figure 4 - Excerpt of the Gamification Tutoring Ontology (GaTO). Some classes and relations are omitted for clarity. We use the prefix "gt" to refer to the concepts within GaTO ontology and "its" to refer to concepts from Bittencourt's ontology.

\subsection{Evaluation and statistical results}

To evaluate the ontological model, we used the FOCA methodology (Bandeira et al., 2016) since, in comparison to other ontologies evaluation strategies, it strongly relies on the knowledge representation principles and on constructs of other evaluation strategies to define a set of objective criteria to evaluate ontologies. The evaluation involved the participation of human agents. Five people with experience in the use of ontologies and on the ontologies' domain topics (gamification and ITS) were selected. Four of them are from academic settings (Ms.C or Ph.D. students) and one participant came from industry. All participants had prior knowledge on ontology and prior experience with the Protégé tool. For each ontology of our model, participants were introduced to the ontologies along with their documentation through a survey asking participants to answer the questions defined by the FOCA methodology, for instance, related to knowledge representation roles, i.e., substitute, ontological commitment, intelligent reasoning, and computational efficiency). We also collected qualitative data about the positive and negative aspects of the ontologies.

The qualitative results of the ontologies' evaluation suggest that they provide a good abstraction of the domain. The quantitative results allowed us to state: (i) there is significance on the effects of the ontology factor in the Substitute score (p-value $=0: 01557$ ) and in the Overall score (p-value =0:0977); (ii) the Substitute score of the GaDO-core ontology is lower than the scores of GaDO-full and GaTO ontologies - p-values are 0:01587 and 0:01597, respectively; (iii) the Intelligent Reasoning score of the GaDO-core ontology is lower (p-value $=0: 5547$ ) than the score of the GaTO; (iv) the Overall Score of the GaDO-core ontology is lower (p-value = 0:05556) than the score of the GaTO ontology; (v) there is no significance on the effects of the ontology factor in the Ontological Commitment and Computational Efficiency scores; and (vi) there is no 
statistical difference between the GaDO-full and GaTO ontologies regarding the Substitute score as well as in the Overall Score.

\section{AGITS: an authoring solution for designing gamified ITS}

In this section, we describe our third contribution, AGITS, an authoring solution developed to aid teachers co-designing gamified ITS. AGITS makes use of the gamified ITS ontology-based feature model (Section 4) to automatically manage the variability of gamified ITS that can be produced using the authoring tool and relies on the GaTO ontological model (Section 5) to constrain the variability design space and to better support the authoring process for teachers.

AGITS implements an authoring process that leverages teachers' intelligence in the Domain model, Pedagogical model, and Gamification model (i.e., in terms of the selection of a behavior, as shown in Table 1) activities of the gamified ITS development process as well as supports extra configurations (e.g., reports presented in the tutor, evaluation methods supported, and so on). The Student model relies on the artificial intelligence features of tutors to automatic represent and update student models based on learner's actions (e.g., interaction with the content, performance on the subjects, strengths, and weaknesses of the students, and so on). Hence, to not overload teachers with more authoring options, we decided to take more advantage of the artificial intelligence instead of human intelligence of teachers in this activity. Moreover, we also found some technological limitations that do not favor simple and usable authoring of the Interface model, thus we also decided to not support authoring for such activity.

As the target users of AGITS are teachers, it is of utmost importance to the success of the solution to be simple and with high usability. At the same time, teachers should feel they are in the control with respect to the gamified ITS they are authoring. Hence, it is also necessary to provide a fair level of flexibility in the authoring process. In this way, the design of the authoring solution considers the trade-off between usability and flexibility non-functional requirements (Murray, 2004; Dag et al., 2014; Sottilare et al., 2015).

The authoring process supported by AGITS allows the customization of gamified ITS features in two alternative flows, one creating a tutor from scratch and the other applying a configuration template. Figure 5 presents two screens of the developed authoring solution. The first picture (on the left) shows AGITS starting screen enabling authoring in two different ways: from scratch or using a template. The second picture (on the right) shows the beginning screen for authoring by applying a configuration template. Note that the authoring process is constrained by theories and evidence-supported practices conceptualized in the GaTO ontological model. For using the authoring solution, teachers can make several authoring decisions (e.g., the domain of the tutor, the gamified behavior he/she expects from his/her students, and so on), which are supported by the knowledge represented in the ontological model (see Figure 2). 


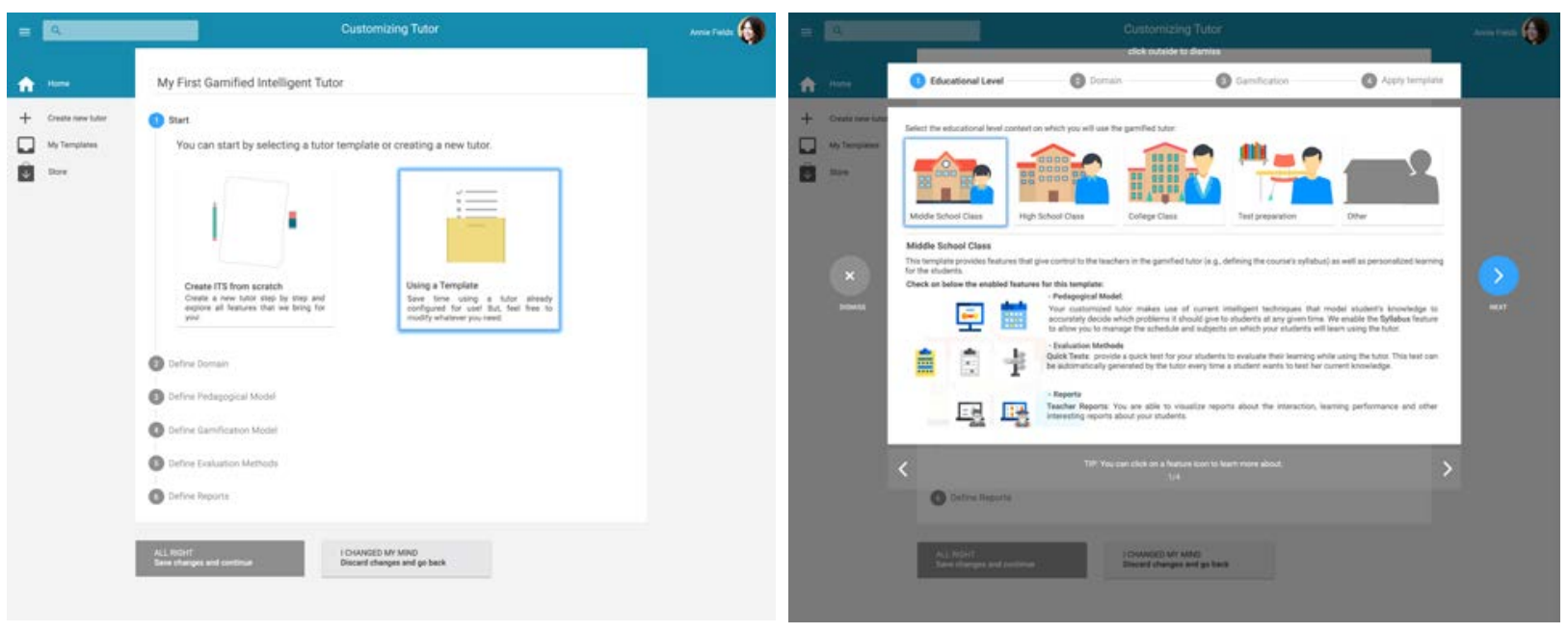

Figure 5 - AGITS prototypes

\subsection{Evaluation and statistical results}

To evaluate our authoring solution, we conducted two experiments to understand the perceptions of teachers with respect to the authoring solution.

The first experiment intended to analyze non-interactive prototypes of the authoring solution combining two ways for authoring (template and scratch) vs. two ways for gamification authoring (selecting behaviors or game design elements) to evaluate them with respect to several metrics such as perceived ease of use, perceived usability, complexity, aesthetics, novelty, unity, intensity, attitude towards use, perceived system support, and credibility from the viewpoint of teachers in the context of graduate students and researchers, from two research groups in Brazil and Canada ${ }^{4}$, analyzing the prototypes and answering a survey. A $2 \times 2$ between-subjects design was used, on which 57 participants were shown only one of the four possible versions of the prototypes. Note that the version on which a participant evaluated the prototypes was randomly allocated to him. Participants were asked to answer questions regarding the prototypes and a Likert scale was used for measuring the variables.

The main results of this experiment were (i) the average scores of all metrics for the four versions evaluated on a Likert scale from 1 to 7 are greater than 5 (partially agree), for some versions (e.g., perceived ease of use, and attitude towards use of the version 1), greater than 6 (agree); and (ii) despite there is no statistical difference between the version with regards the credibility metric, the credibility average score (scale from 1 to 9) of version 1 (template and behavior) received the highest score of 8.2, followed by version 4 (scratch and game design elements) with 7.886, version 3 (template and game design elements) with 7.625, and version 4 (scratch and behavior) with 6.9231.

After conducting the first experiment, AGITS was improved based on the results collected from participants and a second experiment was performed. This new experiment intended to analyze the authoring process by using template or scratch in AGITS to evaluate them regarding

\footnotetext{
4 This experiment was performed when this author was in the Ph.D. sandwich at the University of Saskatchewan (Canada) under the supervision of Professor Julita Vassileva.
} 
ease of use, usability, low complexity, and authoring time from the viewpoint of teachers in the context of teachers in Brazil interacting with the prototypes and answering a survey about the authoring process. We used a full-factorial design, on which 41 participants were shown the two authoring flows (scratch or template). Each participant interacted with both versions (the order of interaction was randomized). Participants were asked to answer demographic questions as well as about the authoring tool. Time was measured by the system designed to instrument the experiment and a Likert scale from 1 (completely disagree) to 7 (completely agree) is used for the other variables (i.e., ease of use, usability, and low complexity). To compute the overall score of the metrics, for the variables that include more than one question, we calculated the average of the variable according to the answer to each variable's question. Table 2 presents research hypotheses that are investigated in the second experiment.

Table 2 - Hypotheses of the second experiment

\begin{tabular}{l}
\hline H1: The complexity of the versions is equal \\
H2: The usefulness of the versions is equal \\
\hline H3: The authoring time using the versions is equal \\
H4: The perceived ease of use (PEU) of the versions is equal \\
H5: The usability of the versions is equal \\
\hline H6: The attitude towards use of the versions is equal \\
\hline H7: The behavioral intention to use of the versions is equal \\
H8: The perceived system support of the versions is equal \\
H9: The credibility of the versions is equal \\
H10: The perceived representability of the tutor authored using the versions is equal \\
\hline H11: The perceived satisfaction of the tutor authored using the versions is equal \\
H12: The perceived utility of the tutor authored using the versions is equal
\end{tabular}

Similarly to previous study, the experiment involves the participation of human agents. Participants were teachers and professors, working at different educational levels, and were invited in one of the following ways: (i) by sending e-mail invitations to all professors of the Federal University of Alagoas; (ii) by sending email invitations to teachers registered in the Brazilian Conference on Computers and Education (2015); (iii) by sending invitation e-mails to the computers and education mailing list; and (iv) posting an invitation on the computers and education Facebook group. It is worth noting that before sending these invitations, we conducted a pilot study in laboratory settings (i.e, in our research group) to receive feedback and to adjust our instruments.

In Table 3, we present the summary of statistics (e.g., median, mean, sd) and the results of the normality tests (e.g., Shapiro-Wilk and Anderson-Darling tests) we applied for the perceived ease of use (PEU), usability (U), complexity (C), usefulness (USE), attitude towards use (ATU), behavioral intention to use (BIU), perceived system support (PSS), credibility (CR), time (T), representability (R), satisfaction (S), and utility (UTI) metrics per version analyzed in this experiment.

Table 3 - Summary of statistics and normality tests for the ten metrics evaluated per version. Std. Dev. = Standard Deviation, S$\mathrm{W}=$ Shapiro-Wilk, and A-D = Anderson-Darling.

\begin{tabular}{|l|r|r|r|r|r|r|r|r|r|r|r|r|}
\hline & PEU & U & C & USE & ATU & BIU & PSS & CR & Time (min) & R & S & UTI \\
\hline $\begin{array}{l}\text { Version 1 } \\
\text { (N=36) }\end{array}$ & & & & & & & & & & & \\
\hline Min & 3 & 2 & 2.333 & 1 & 1.667 & 1 & 1.333 & 2 & 1.31 & 3 & 3 & 2 \\
\hline Max & 7 & 7 & 7 & 7 & 7 & 7 & 7 & 9 & 15.473 & 9 & 9 & 9 \\
\hline Range & 4 & 5 & 4.667 & 6 & 5.333 & 6 & 5.667 & 7 & 14.163 & 6 & 6 & 7 \\
\hline Median & 5.9 & 5.5 & 5.667 & 3 & 6 & 5.833 & 5.333 & 7 & 5.088 & 8 & 7 & 8 \\
\hline
\end{tabular}




\begin{tabular}{|c|c|c|c|c|c|c|c|c|c|c|c|c|}
\hline Mean & 5.661 & 5.306 & 5.306 & 3.076 & 5.574 & 5.269 & 5.278 & 6.833 & 5.519 & 7.25 & 7 & 7.361 \\
\hline Std. Dev. & 0.987 & 1.027 & 1.158 & 1.655 & 1.086 & 1.423 & 1.128 & 1.682 & 3.284 & 1.697 & 1.805 & 1.9 \\
\hline S-W (p-value) & 0.023 & 0.088 & 0.024 & 0.025 & 0.001 & 0 & 0.008 & 0.004 & 0.035 & 0 & 0.003 & 0 \\
\hline A-D (p-value) & 0.025 & 0.297 & 0.042 & 0.064 & 0.007 & 0 & 0.042 & 0.005 & 0.164 & 0 & 0.003 & 0 \\
\hline Normal? & 0 & 1 & 0 & 1 & 0 & 0 & 0 & 0 & 1 & 0 & 0 & 0 \\
\hline \multicolumn{13}{|l|}{$\begin{array}{l}\text { Version } 2 \\
(\mathrm{~N}=41)\end{array}$} \\
\hline Min & 2 & 1.8 & 1.667 & 1 & 1 & 1 & 1.667 & 3 & 0.45 & 2 & 2 & 1 \\
\hline Max & 7 & 7 & 7 & 7 & 7 & 7 & 7 & 9 & 14.74 & 9 & 9 & 9 \\
\hline Range & 5 & 5.2 & 5.333 & 6 & 6 & 6 & 5.333 & 6 & 14.29 & 7 & 7 & 8 \\
\hline Median & 5.6 & 5 & 5 & 3 & 5 & 5 & 5 & 7 & 2.607 & 7 & 7 & 7 \\
\hline Mean & 5.537 & 5.151 & 5.049 & 3.006 & 5.154 & 5.057 & 5.008 & 6.829 & 3.367 & 6.78 & 6.537 & 6.805 \\
\hline Std. Dev. & 1.185 & 1.15 & 1.284 & 1.266 & 1.401 & 1.52 & 1.248 & 1.611 & 2.727 & 1.93 & 1.818 & 2.076 \\
\hline S-W (p-value) & 0.009 & 0.058 & 0.075 & 0.081 & 0.003 & 0.007 & 0.034 & 0.009 & 0 & 0.001 & 0.028 & 0.001 \\
\hline A-D (p-value) & 0.053 & 0.114 & 0.114 & 0.23 & 0.007 & 0.03 & 0.032 & 0.006 & 0.001 & 0.002 & 0.033 & 0.001 \\
\hline Normal? & 1 & 1 & 1 & 1 & 0 & 1 & 0 & 0 & 0 & 0 & 0 & 0 \\
\hline
\end{tabular}

Table 4 presents the results after applying the tests for the hypotheses of this experiment. The hypotheses, applied test, $\mathrm{p}$-value, and the decision if the resultant $\mathrm{p}$-value is enough to reject (p-value < 0.05) or not the null hypothesis (i.e., there is no difference between the factors) are presented in this table. As shown, we found statistical significance for the hypothesis H9 (time for authoring). This result might suggest that using templates demand less time from teachers than authoring from scratch. Note that this result was expected, since we provide, in this version, preconfigured gamified ITS by educational levels that demand fewer choices by teachers. However, this is not obvious since we are investigating the use of additional features that may require some cognitive effort from teachers to understand.

Additionally, regarding the authoring tool process using both versions, there is no statistical difference with regards to the following dependent variables for the comparison between the two versions: perceived ease of use, usability, complexity, usefulness, attitude towards use, behavioral intention to use, perceived system support, and credibility. One might note that not finding significant differences between the versions is not necessarily a bad result. In fact, as presented in Table 3, the average scores received per metric for both versions may be considered positive. The perceived ease of use, usability, complexity, attitude towards use, and behavioral intention to use receive average scores above 5 (agree). Note that the complexity metric is measured with negative assertions, i.e., high scores in this metric indicate simpler prototypes. The usefulness metric also presents negative assertions and presents average scores close to 3 (disagree). For the credibility score, the average score for both versions is close to 7 (in a scale from 1 to 9). With respect to the three metrics (representability, satisfaction, and utility) that are related to the gamified ITS prototypes generated after teachers have chosen the features of their tutors, we could not find a statistical difference between the versions. However, we might also note that the average score for these metrics is also close to 7 (in a scale from 1 to 9).

Table 4 - P-value results for the hypotheses of the second experiment

\begin{tabular}{lllrl}
\hline Hypothesis & Metric & Method & p-value & Decision (95\%) \\
\hline H1 & Perceived ease of use & $\begin{array}{l}\text { Wilcoxon rank sum test with continuity } \\
\text { correction }\end{array}$ & 0.643764588 & Fail to reject \\
\hline H2 & Usability & Welch Two Sample t-test & 0.535877832 & Fail to reject \\
\hline
\end{tabular}




\begin{tabular}{|c|c|c|c|c|}
\hline H3 & Complexity & $\begin{array}{l}\text { Wilcoxon rank sum test with continuity } \\
\text { correction }\end{array}$ & 0.387900237 & Fail to reject \\
\hline H4 & Usefulness & Welch Two Sample t-test & 0.836533973 & Fail to reject \\
\hline H5 & Attitude towards use & $\begin{array}{l}\text { Wilcoxon rank sum test with continuity } \\
\text { correction }\end{array}$ & 0.191883734 & Fail to reject \\
\hline H6 & $\begin{array}{l}\text { Behavioral intention to } \\
\text { use }\end{array}$ & $\begin{array}{l}\text { Wilcoxon rank sum test with continuity } \\
\text { correction }\end{array}$ & 0.459741939 & Fail to reject \\
\hline H7 & Perceived system support & $\begin{array}{l}\text { Wilcoxon rank sum test with continuity } \\
\text { correction }\end{array}$ & 0.286745514 & Fail to reject \\
\hline H8 & Credibility & $\begin{array}{l}\text { Wilcoxon rank sum test with continuity } \\
\text { correction }\end{array}$ & 0.950243262 & Fail to reject \\
\hline H9 & Time & Wilcoxon rank sum test & 0.00081419 & Reject \\
\hline H10 & Representability & $\begin{array}{l}\text { Wilcoxon rank sum test with continuity } \\
\text { correction }\end{array}$ & 0.312598008 & Fail to reject \\
\hline H11 & Satisfaction & $\begin{array}{l}\text { Wilcoxon rank sum test with continuity } \\
\text { correction }\end{array}$ & 0.252061798 & Fail to reject \\
\hline H12 & Utility & $\begin{array}{l}\text { Wilcoxon rank sum test with continuity } \\
\text { correction }\end{array}$ & 0.191234576 & Fail to reject \\
\hline
\end{tabular}

Taken together, our results might suggest that in general teachers have positive perceptions regarding the two ways for customizing gamified ITS features. Thus, despite the version 1 requires less time to author gamified ITS than the version 2, one might say that participants somehow agreed that both of our authoring solution versions are ease to use, usable, and simple. Our results also indicate that teachers have a positive attitude towards the use of both versions of our authoring solution, moreover, it may also suggest that teachers behave with intention to use our solution and perceive that our versions provide support for completing the authoring task. Finally, teachers are also likely to agree that the authored gamified ITS prototypes are perceived to be representative of the choices made by them during the authoring process. Teachers are also amenable to be satisfied by the authored prototypes and find them helpful for their students.

\section{Related Works}

To identify related works to our authoring solution, we compare our proposal to the works identified in a recent systematic literature review on the use of authoring tools to design ITS for non-programmer authors (Dermeval et al., 2018).

The papers (Aleven, McLaren, \& Sewall, 2009; Aleven et al., 2016; Blessing, Gilbert, Ourada, \& Ritter, 2009; Brawner, 2015; Gilbert, Blessing, \& Guo, 2015; Guin \& Lefevre, 2013; MacLellan, Koedinger, \& Matsuda, 2014; MacLellan et al., 2015; Matsuda, Cohen, \& Koedinger, 2015; Olsen et al., 2014; Wilches \& Palacio, 2014) included in the review by Dermeval et al., (2018) are somehow dealing with variability inherent to ITS. However, among these papers, none of them are using a strategic reuse approach such as feature model or software product line to manage such variability. Moreover, some papers (Abbas, Ahmad, \& Kalid, 2014; Grubisic, Stankov, \& Glavinic, 2009; Refanidis, 2011; Suraweera, Mitrovic, \& Martin, 2010) rely on ITS formal representation (i.e., using ontologies) to deal with the knowledge involved in ITS design. Most of these works are aiding teachers in defining the domain model of tutors as well as relying on the reasoning and inference capabilities provided by ontologies to effectively use the domain model during tutoring. Four papers (Abbas et al., 2014; Escudero \& Fuentes, 2010; Troussas, Alepis, Virvou, \& Ieee, 2014; Virvou \& Troussas, 2011) are providing some kind of reuse feature in different aspect of ITS authoring such as to reuse domain and content and tutors design. However, none of these papers are targeting the authoring of gamified ITS. Our authoring tool proposal also provides for teachers features for reusing pre-configured gamified tutor designs and domain models in order to make the authoring process simpler and more usable. 
We also identified some works than can be considered related to ours, since they apply gamification in ITS (González, Mora, \& Toledo, 2014; Andrade, Mizoguchi, \& Isotani, 2016; Shi \& Cristea, 2016). González et al. (2014) propose a conceptual architecture for building ITS taking into account gamification elements. Andrade et al. (2016) identify some problems about the use of gamification in existing gamified environments of the literature (e.g., addiction, undesired competition, and off-task behavior). For addressing such problems, they propose a framework to support the personalization of gamification for ITSs. Shi and Cristea (2016) explores how to approach gamification in social adaptive e-learning based on the Self-Determination Theory.

Although these works present interesting approaches for using gamification in connection with ITS, they do not formally represent neither the knowledge about gamification theories nor the knowledge about ITS theories as well as how they are connected. In our work, we take advantage of ontologies to represent such knowledge in order to support the development of an authoring tool that could intelligently design gamified ITS relying both on human and teachers intelligence.

\section{Conclusions}

In this paper we presented a solution to allow teachers co-designing gamified intelligent tutoring systems. This solution makes use of an ontology-based feature model (specified based on the OntoSPL ontology proposed) to enable the management of the variability of gamified ITS features that were identified. The authoring solution also takes advantage of an integrated ontological model (GaTO) that connects gamification and ITS concepts as well as design principles in order to constrain the variability space of gamified ITS based on such theories and practices and to aid managing the design of gamified ITS in an intoperable way.

The results found so far indicate a promising way to explore the use of authoring tools, ontologies, and software engineering techniques to take advantage of both artificial intelligence techniques (mainly for aiding adaptation for students) as well as on the human intelligence of teachers to co-design gamified intelligent tutoring systems. The practical implications of this research are mainly related to the empowerment of teachers towards an active and personalized use of gamified and adaptive systems for their students. In addition, as teachers play a key role in introducing pedagogical innovations in classrooms, empowering them is of utmost importance to the effective use of these systems by students. Our proposal might consider teachers as first-class citizens in the use of gamified and adaptive tutoring systems for higher education.

Our investigations were limited to the combination of teachers and artificial intelligence to design gamified and adaptive tutoring systems at pre-instruction time, i.e., before students start to learn by using the system. However, once there are several pieces of evidence in support of the effectiveness of ITS to improve learning outcomes in education, we intend to further investigate how to amplify teachers' participation to provide gamified and adaptive instruction for the tutor life-cycle. We mean that in addition to being merely used to develop ITS, these solutions might be strategic to manage tutoring systems at other stages since it is by using these tools that tutors are generated. We argue that, beyond using ITS authoring tools to develop tutor before students use it, authoring tools could also enable authors to act, for example, at critic learning situations in order to avoid students dropping out the tutor, to allow reconfiguration of tutors after a tutoring cycle to improve the tutor, and so on. 


\section{References}

Abbas, M. A., Ahmad, W. F. W., \& Kalid, K. S. (2014). Semantic Web Technologies for PreSchool Cognitive Skills Tutoring System. Journal of information science and engineering, 30(3), 835-851. [GS Search]

Aleven, V., McLaren, B. M., \& Sewall, J. (2009). Scaling Up Programming by Demonstration for Intelligent Tutoring Systems Development: An Open-Access Web Site for Middle School Mathematics Learning. Learning Technologies, IEEE Transactions on, 2(2), 64-78. DOI: https://doi.org/10.1109/TLT.2009.22. [GS Search]

Aleven, V., McLaren, B. M., Sewall, J., van Velsen, M., Popescu, O., Demi, S., . . . Koedinger, K. R. (2016). Example-tracing tutors: Intelligent tutor development for non-programmers. International Journal of Artificial Intelligence in Education, 26(1), 224-269. DOI: https://doi.org/10.1007/s40593-015-0088-2. [GS Search]

Andrade, F. R. H., Mizoguchi, R., \& Isotani, S. (2016). The bright and dark sides of gamification. In A. Micarelli, J. Stamper, \& K. Panourgia (Eds.), Intelligent tutoring systems: 13th international conference, its 2016, zagreb, croatia, june 7-10, 2016. proceedings (pp. 176186). Cham: Springer International Publishing. DOI: https://doi.org/10.1007/978-3-31939583-8_17. [GS Search]

Baker, R. S., D’Mello, S. K., Rodrigo, M. M. T., \& Graesser, A. C. (2010). Better to be frustrated than bored: The incidence, persistence, and impact of learners' cognitive-affective states during interactions with three different computer-based learning environments. International Journal of Human-Computer Studies, 68(4), 223-241. DOI: https://doi.org/10.1016/j.ijhcs.2009.12.003. [GS Search]

Bandeira, J., Bittencourt, I. I., Espinheira, P., \& Isotani, S. (2016). Foca: A methodology for ontology evaluation. arXiv preprint arXiv:1612.03353. [GS Search]

Beck, J., Stern, M., \& Haugsjaa, E. (1996). Applications of ai in education. Crossroads, 3(1), 1115. DOI: https://doi.org/10.1145/332148.33215. [GS Search]

Bittencourt, I. I., Costa, E., Silva, M., \& Soares, E. (2009). A computational model for developing semantic web-based educational systems. Knowledge-Based Systems, 22(4), 302 - 315. DOI: http://dx.doi.org/10.1016/j.knosys.2009.02.012. [GS Search]

Blessing, S. B., Gilbert, S. B., Ourada, S., \& Ritter, S. (2009). Authoring model-tracing cognitive tutors. International Journal of Artificial Intelligence in Education, 19(2), 189-210. DOI: https://dl.acm.org/doi/10.5555/1734243.1734247. [GS Search]

Brawner, K. W. (2015). Rapid dialogue and branching tutors. In Proceedings of the workshops at the 17th international conference on artificial intelligence in education, AIED 2015, madrid, spain, june $22+26,2015$. [GS Search]

Clements, P. C., \& Northrop, L. (2001). Software product lines: Practices and patterns. AddisonWesley. [GS Search]

Czarnecki, K., Peter Kim, C. H., \& Kalleberg, K. T. (2006). Feature models are views on ontologies. In Proceedings of the 10th international on software product line conference (pp. 41-51). Washington, DC, USA: IEEE Computer Society. DOI: https://doi.org/10.1109/SPLINE.2006.1691576. [GS Search]

Dag, F., Durdu, L., \& Gerdan, S. (2014). Evaluation of educational authoring tools for teachers stressing of perceived usability features. Procedia-Social and Behavioral Sciences, 116, 888901. DOI: https://doi.org/10.1016/j.sbspro.2014.01.316. [GS Search]

Dermeval, D., Tenório, T., Bittencourt, I. I., Silva, A., Isotani, S., \& Ribeiro, M. (2015). Ontologybased feature modeling: An empirical study in changing scenarios. Expert Systems with Applications, 42(11), 4950-4964. DOI: https://doi.org/10.1016/j.eswa.2015.02.020. [GS Search] 
Dermeval, D., \& Bittencourt, I. I. (2017). Authoring gamified intelligent tutoring systems. In Anais dos Workshops do Congresso Brasileiro de Informática na Educação (Vol. 6, No. 1, p. 14). DOI: http://dx.doi.org/10.5753/cbie.wcbie.2017.14. [GS Search]

Dermeval, D., Paiva, R., Bittencourt, I. I., Vassileva, J., \& Borges, D. (2018). Authoring tools for designing intelligent tutoring systems: a systematic review of the literature. International Journal of Artificial Intelligence in Education, 1-49. DOI: https://doi.org/10.1007/s40593017-0157-9. [GS Search]

de Sousa Borges, S., Durelli, V. H., Reis, H. M., \& Isotani, S. (2014). A systematic mapping on gamification applied to education. In Proceedings of the 29th annual acm symposium on applied computing (pp. 216-222). DOI: https://doi.org/10.1145/2554850.2554956. [GS $\underline{\text { Search }] ~}$

Deterding, S., Dixon, D., Khaled, R., \& Nacke, L. (2011). From game design elements to gamefulness: defining gamification. In Proceedings of the 15th international academic mindtrek conference: Envisioning future media environments (pp. 9-15). DOI: https://doi.org/10.1145/2181037.2181040. [GS Search]

Dillenbourg, P., \& Self, J. (1992). A framework for learner modelling. Interactive Learning Environments, 2(2), 111-137. DOI: https://doi.org/10.1080/1049482920020202. [GS $\underline{\text { Search] }}$

Du Boulay, B. (2016). Recent meta-reviews and meta-analyses of aied systems. International Journal of Artificial Intelligence in Education, 26(1), 536-537. DOI: https://doi.org/10.1007/s40593-015-0060-. [GS Search]

Du Boulay, B., \& Luckin, R. (2001). Modelling human teaching tactics and strategies for tutoring systems. International Journal of Artificial Intelligence in Education, 12(3), 235-256. DOI: https://doi.org/10.1007/s40593-015-0053-0. [GS Search]

Escudero, H., \& Fuentes, R. (2010). Exchanging courses between different Intelligent Tutoring Systems: A generic course generation authoring tool. Knowledge-Based Systems, 23(8), 864-874. DOI: https://doi.org/10.1016/j.knosys.2010.05.01. [GS Search]

Gilbert, S. B., Blessing, S. B., \& Guo, E. (2015). Authoring Effective Embedded Tutors: An Overview of the Extensible Problem Specific Tutor (xPST) System. International Journal of Artificial Intelligence in Education, NA. DOI: https://doi.org/10.1007/s40593-015-0045-0. [GS Search]

Gómez-Pérez, A. (1996). Towards a framework to verify knowledge sharing technology. Expert Systems with Applications, 11(4), 519-529. DOI: https://doi.org/10.1016/S09574174(96)00067-X. [GS Search]

González, C., Mora, A., \& Toledo, P. (2014). Gamification in intelligent tutoring systems. In Proceedings of the second international conference on technological ecosystems for enhancing multiculturality (pp. 221-225). New York, NY, USA: ACM. DOI: https://doi.org/10.1145/2669711.2669903. [GS Search]

Gruber, T. R. (1993, June). A translation approach to portable ontology specifications. Knowl. Acquis., 5(2), 199-220. [GS Search]

Grubisic, A., Stankov, S., \& Glavinic, V. (2009). Agent based intelligent courseware generation in e-learning. Proceeding of the IASTED International Conference on Computers and Advanced Technology in Education (CATE). [GS Search]

Guin, N., \& Lefevre, M. (2013). From a customizable ITS to an adaptive ITS. International Conference on Artificial Intelligence in Education (AIED), 7926 LNAI, 141-150. DOI: https://doi.org/10.1007/978-3-642-39112-5_15. [GS Search]

Hamari, J., Koivisto, J., \& Sarsa, H. (2014). Does gamification work?-a literature review of empirical studies on gamification. In System sciences (hicss), 2014 47th hawaii international conference on (pp. 3025-3034). DOI: https://doi.org/10.1109/HICSS.2014.377. [GS Search] 
Huotari, K., \& Hamari, J. (2012). Defining gamification: a service marketing perspective. In Proceeding of the 16th international academic mindtrek conference (pp. 17-22). DOI: https://doi.org/10.1145/2393132.2393137. [GS Search]

Lemann, F. (2015). Conselho de classe: A viso dos professores sobre a educação no brasil. Disponível em http://fundacaolemann.org.br/novidades/a-visao-dos-professores-sobre-aeducacaono-brasil. (Acesso em 23 de Julho de 2015).

Ma,W., Adesope, O. O., Nesbit, J. C., \& Liu, Q. (2014). Intelligent tutoring systems and learning outcomes: A meta-analysis. Journal of Educational Psychology, 901-918. DOI: http://dx.doi.org/10.1037/a0037123. [GS Search]

MacLellan, C. J., Harpstead, E., Wiese, E. S., Zou, M., Matsuda, N., Aleven, V., \& Koedinger, K. R. (2015). Authoring tutors with complex solutions: A comparative analysis of example tracing and simstudent. In Proceedings of the workshops at the 17th international conference on artificial intelligence in education, AIED 2015, Madrid, Spain, 2015. [GS Search]

MacLellan, C. J., Koedinger, K. R., \& Matsuda, N. (2014). Authoring Tutors with SimStudent: An Evaluation of Efficiency and Model Quality. Intelligent Tutoring Systems, NA. DOI: https://doi.org/10.1007/978-3-319-07221-0_70. [GS Search]

Martá-Parreño, J., Seguí-Mas, D., \& Seguí-Mas, E. (2016). Teachers’ attitude towards and actual use of gamification. Procedia-Social and Behavioral Sciences, 228, 682-688. DOI: https://doi.org/10.1016/j.sbspro.2016.07.104. [GS Search]

Matsuda, N., Cohen, W.W., \& Koedinger, K. R. (2015). Teaching the Teacher: Tutoring SimStudent Leads to More Effective Cognitive Tutor Authoring. International Journal of Artificial Intelligence in Education, 25(1).DOI: https://doi.org/10.1007/s40593-014-0020-1. [GS Search]

Murray, T. (2003). An overview of intelligent tutoring system authoring tools: Updated analysis of the state of the art. In Authoring tools for advanced technology learning environments (pp. 491-544). Springer. DOI: https://doi.org/10.1007/978-94-017-0819-7_17. [GS Search]

Murray, T. (2004). Design tradeoffs in usability and power for advanced educational software authoring tools. EDUCATIONAL TECHNOLOGY-SADDLE BROOK THEN ENGLEWOOD CLIFFS NJ-, 44(5), 10-16. [GS Search]

Nacke, L. E., \& Deterding, S. (2017). The maturing of gamification research. Elsevier. DOI: https://doi.org/10.1016/j.chb.2016.11.062. [GS Search]

Olsen, J. K., Belenky, D. M., Aleven, V., Rummel, N., Sewall, J., \& Ringenberg, M. (2014). Authoring Tools for Collaborative Intelligent Tutoring System Environments. Intelligent Tutoring Systems, NA. DOI: https://doi.org/10.1007/978-3-319-07221-0_66. [GS Search]

ProjectTomorrow. (2013). Learning in the 21st century: Digital experiences and expectations of tomorrow's teachers. Disponível em http://www.tomorrow.org/speakup/tomorrowsteachers report2013.html. (Acesso em 23 de Julho de 2015)

ProjectTomorrow. (2014). Speak up 2014 research project findings - the results of the authentic, unfiltered views of 41,805 k-12 teachers nationwide. Disponível em http://www.tomorrow.org/speakup/pdfs/SU2014 TeacherTop10.pdf. (Acesso em 23 de Julho de 2015)

Refanidis, D. S. (2011). The MATHESIS Semantic Authoring Framework: Ontology-Driven Knowledge Engineering for ITS Authoring. Knowlege-Based and Intelligent Information and Engineering Systems, NA. DOI: https://doi.org/10.1007/978-3-642-23863-5_12. [GS $\underline{\text { Search }]}$

Salen, K., \& Zimmerman, E. (2004). Rules of play: Game design fundamentals. MIT press. [GS $\underline{\text { Search }] ~}$

Seaborn, K., \& Fels, D. I. (2015). Gamification in theory and action: A survey. International Journal of Human-Computer Studies, 74, 14-31. [GS Search]

Shi, L., \& Cristea, A. I. (2016). Motivational gamification strategies rooted in self-determination theory for social adaptive e-learning. In A. Micarelli, J. Stamper, \& K. Panourgia (Eds.), 
Intelligent tutoring systems: 13th international conference, its 2016, zagreb, croatia, June 710, 2016. proceedings (pp. 294-300). Cham: Springer International Publishing. DOI: https://doi.org/10.1007/978-3-319-39583-8_32. [GS Search]

Shute, V. J., \& Psotka, J. (1994). Intelligent tutoring systems: Past, present, and future. (Tech. Rep.). DTIC Document. [GS Search]

Silva, A., Costa, E., \& Bittencourt, I. I. (2012). Uma linha de produto de software baseada na web semântica para sistemas tutores inteligentes. Revista Brasileira de Informática na Educação, 20(1), 87. DOI: http://dx.doi.org/10.5753/rbie.2012.20.1.87. [GS Search]

Sleeman, D., \& Brown, J. S. (1982). Intelligent tutoring systems. London: Academic Press. [GS $\underline{\text { Search] }}$

Sottilare, R., Graesser, A., Hu, X., \& Brawner, K. (2015). Design recommendations for intelligent tutoring systems: Authoring tools and expert modeling techniques. Robert Sottilare. [GS Search]

Suraweera, P., Mitrovic, A., \& Martin, B. (2010). Widening the knowledge acquisition bottleneck for constraint-based tutors. International Journal of Artificial Intelligence in Education, 20(2), 137-173. DOI: http://dx.doi.org/10.3233/JAI-2010-0005. [GS Search]

Troussas, C., Alepis, E., Virvou, M., \& Ieee. (2014). Mobile authoring in a multiple language learning environment. Proceedings of the 5th International Conference on Information, Intelligence, Systems and Applications, Iisa 2014, 405-+. DOI: https://doi.org/10.1109/IISA.2014.6878819. [GS Search]

Virvou, M., \& Troussas, C. (2011). Knowledge-Based Authoring Tool for Tutoring Multiple Languages. Intelligent Interactive Multimedia Systems and Services, NA. DOI: https://doi.org/10.1007/978-3-642-22158-3_17. [GS Search]

Werbach, K., \& Hunter, D. (2012). For the win: How game thinking can revolutionize your business. Wharton Digital Press. [GS Search]

Wilches, C. O. E., \& Palacio, G. V. H. (2014). Development of example-tracing tutors for teaching control systems performance fundamentals. In Proceedings of the 4th world congress on information and communication technologies, wict (pp. 290-295). [GS Search]

Woolf, B. P. (2010). Building intelligent interactive tutors: Student-centered strategies for revolutionizing e-learning. Morgan Kaufmann. [GS Search] 